\title{
Characterization of neutralizing epitopes within the major capsid protein of human papillomavirus type 33
}

\author{
Stefanie D Roth ${ }^{1}$, Martin Sapp ${ }^{1,2,3,4}$, Rolf E Streeck ${ }^{1}$ and Hans-Christoph Selinka*1
}

Address: ${ }^{1}$ Institute for Medical Microbiology, Johannes Gutenberg-University 55101 Mainz, Germany, ${ }^{2}$ Center for Molecular and Tumor Virology, Louisiana State University Health Sciences Center, 1501 Kings Highway, Shreveport, LA 71130, USA, ${ }^{3}$ Feist Weiller Cancer Center, Louisiana State University Health Sciences Center, 1501 Kings Highway, Shreveport, LA 71130, USA and ${ }^{4}$ Department of Microbiology and Immunology, Louisiana State University Health Sciences Center, 1501 Kings Highway, Shreveport, LA 71130, USA

Email: Stefanie D Roth - st_roth@gmx.de; Martin Sapp - msapp@lsuhsc.edu; Rolf E Streeck - streeck@uni-mainz.de; HansChristoph Selinka* - selinka@uni-mainz.de

* Corresponding author

\section{Published: 02 October 2006}

Virology Journal 2006, 3:83 doi:10.1 186/1743-422X-3-83

This article is available from: http://www.virologyj.com/content/3/l/83

(c) 2006 Roth et al; licensee BioMed Central Ltd.

This is an Open Access article distributed under the terms of the Creative Commons Attribution License (http://creativecommons.org/licenses/by/2.0), which permits unrestricted use, distribution, and reproduction in any medium, provided the original work is properly cited.
Received: 10 August 2006

Accepted: 02 October 2006

\begin{abstract}
Background: Infections with papillomaviruses induce type-specific immune responses, mainly directed against the major capsid protein, LI. Based on the propensity of the LI protein to selfassemble into virus-like particles (VLPs), type-specific vaccines have already been developed. In order to generate vaccines that target a broader spectrum of HPV types, extended knowledge of neutralizing epitopes is required. Despite the association of human papillomavirus type 33 (HPV33) with cervical carcinomas, fine mapping of neutralizing conformational epitopes on HPV 33 has not been reported yet. By loop swapping between HPV33 and HPVI6 capsid proteins, we have identified amino acid sequences critical for the binding of conformation-dependent type-specific neutralizing antibodies to surface-exposed hyper variable loops of HPV33 capsid protein LI.
\end{abstract}

Results: Reactivities of monoclonal antibodies (mAbs) H33.B6, H33.EI2, H33.J3 and HI6.56E with HPVI6:33 and HPV33:16 hybrid LI VLPs revealed the complex structures of their conformational epitopes as well as the major residues contributing to their binding sites. Whereas the epitope of $\mathrm{mAb} \mathrm{H33.J3}$ was determined by amino acids (aa) $5 \mathrm{I}-58$ in the BC loop of HPV33 LI, sequences of at least two hyper variable loops, DE (aa 132-140) and FGb (aa 282-291), were found to be essential for binding of H33.B6. The epitope of H33.EI2 was even more complex, requiring sequences of the FGa loop (aa 260-270), in addition to loops DE and FGb.

Conclusion: These data demonstrate that neutralizing epitopes in HPV33 LI are mainly located on the tip of the capsomere and that several hyper variable loops contribute to form these conformational epitopes. Knowledge of the antigenic structure of HPV is crucial for designing hybrid particles as a basis for intertypic HPV vaccines.

\section{Background}

Human papillomavirus (HPV) infection is the obligate first step in the development of cervical cancer [1]. However, of the more than 100 types of HPV, only 15 so-called high risk types, most commonly types $16,18,31,33,39$, 45,52 , and 58 , account for at least $95 \%$ of HPV-induced cervical cancer $[2,3]$. Vaccination against these high risk types seems to be the most feasible prevention for cervical 
cancer. Indeed, clinical trials have shown prophylactic HPV vaccines to be effective against HPV infection, cervical intraepithelial neoplasia (CIN), and genital warts, but protection is type-specific and the currently developed vaccines target only a few types [4-6]. These vaccines are based on papillomavirus-like particles (VLPs) composed of the major capsid protein, L1. The L1 protein self assembles into VLPs when expressed at high levels in eukaryotic or insect cells [7-10]. VLPs are composed of 360 copies of L1 protein organized into 72 pentamers, so called capsomeres, to form particles which are immunologically indistinguishable from native virions. Experimentally induced VLP antisera have been shown to be mostly typespecific with respect to neutralization [11-13]. Minor cross-neutralization has been observed only between closely related HPV types, e.g. HPV6 and 11, HPV18 and 45, or HPV16 and 31 [14-16]. Structure analysis has revealed the presence of several hyper variable loops on the outer surface of the capsid [17]. With a few exceptions, all HPV-neutralizing monoclonal antibodies analyzed so far are type-specific and recognize conformational epitopes within surface-exposed hyper variable loops of the major capsid protein L1 [18-21]. Since capsomeres are also potent immunogens for induction of neutralizing antibodies, the formation of these conformational epitopes does not necessarily require capsid assembly $[22,23]$. In a few cases, cross-neutralizing monoclonal antibodies raised against VLPs in animals that recognize surface-exposed linear epitopes have been described $[14,16,21]$.

A prerequisite for generating vaccines that prevent infection with a broad spectrum of HPV types is extended knowledge of viral determinants provoking common and type-specific immune responses. In the present study, we have fine mapped the binding sites of three neutralizing monoclonal antibodies (H33.B6, H33.E12, and H33.J3) with specificity for the human papillomavirus high risk type 33 (HPV33) by site-directed mutagenesis of surfaceexposed amino acids in the major capsid protein L1. Moreover, HPV16:33BC hybrid pseudovirions, formed by HPV16 L1 proteins containing amino acids 51-58 of HPV33 L1 and HPV16 L2, assembled into particles which could be neutralized by both HPV33- and HPV16-specific antibodies, confirming the functional expression of intrinsic and ectopically expressed epitopes.

\section{Results}

\section{Neutralization of HPV33 pseudovirus infection}

Papillomavirus pseudovirions that encapsidate a marker plasmid instead of the viral genome are widely used to study HPV biology and infection, circumventing the difficulties to obtain biochemical quantities of native virions $[12,24]$. Using such HPV16 and HPV33 pseudovirions, we first determined the neutralizing potential of various
HPV-specific antibodies (Fig. 1). Three days post infection with HPV pseudovirions, infection was monitored by the number of cells with green nuclear fluorescence, caused by transmission of a GFP marker gene to the nucleus via the HPV vector. Pseudovirus infection in the presence of the HPV33-specific neutralizing monoclonal antibodies (mAbs H33.B6, H33.J3, and H33.E12) was abolished only with pseudovirions of the respective type. Moreover, we used the recently described mAb H16.56E, generated after immunization with HPV16 VLPs, and also observed type-specific neutralization, demonstrating the validity of this surrogate system for use in testing papillomavirus neutralizing antibodies (Fig. 1A). Binding of these antibodies to conformationally intact HPV VLPs bound to Heparin-BSA-coated Elisa plates confirmed the selective specificity of antibodies H33.J3, H33.B6 and H33.E12 for HPV33 (Fig. 1B). Subsequent experiments were performed to characterize and fine map the epitopes of these HPV33-specific antibodies.

\section{Characterization of hyper variable regions in HPV33 LI}

For various HPV types it has been reported that type-specific monoclonal antibodies primarily reside in surfaceexposed hyper variable loops. Our experimental approach for defining residues involved in neutralization of HPV33 by mAbs H33.B6, H33.J3 and H33.E12 was therefore based on the exchange of type-specific loop sequences between the closely related papillomavirus types 16 and 33. Poorly conserved regions in HPV major capsid proteins $\mathrm{L} 1$ were identified by sequence alignment and localized by RasMol, based on the coordinates of HPV16 (Pdb file 1DZL). As shown in Fig. 2, 30 divergent amino acids between HPV33 and HPV16 were localized in 4 surfaceexposed hyper variable loops, named BC (aa 51-59), DE (aa 132-140), FG (260-291), and HI (346-358), according to the HPV16 L1-structure reported by Chen et al. [17]. In HPV33 L1, the FG loop was found to consist of two separate hyper variable regions, designated in this paper as FGa (260-270) and FGb (282-291) (Fig. 2).

\section{Functional characterization of HPV33 epitopes by loop substitution}

To further characterize the epitopes of HPV33-specific antibodies, hybrid virus-like particles were designed in which type-specific sequences in the major capsid protein L1 of HPV33 were replaced by corresponding amino acids of HPV16, eliminating the putative epitopes. Vice versa, HPV33-specific sequences were introduced into HPV16 L1 for ectopic expression. Ten different hybrid L1 proteins (HPV33:16BC; HPV33:16DE; HPV33:16FGa; HPV33:16FGb; HPV33:16HI; HPV16:33BC; HPV16:33DE; HPV16:33DE/FGa, HPV16:33DE/FGb, and HPV16:33HI) were constructed and expressed in HUTK143 B cells. Western blot analysis revealed that all hybrid proteins were expressed at similar levels (data not shown). 

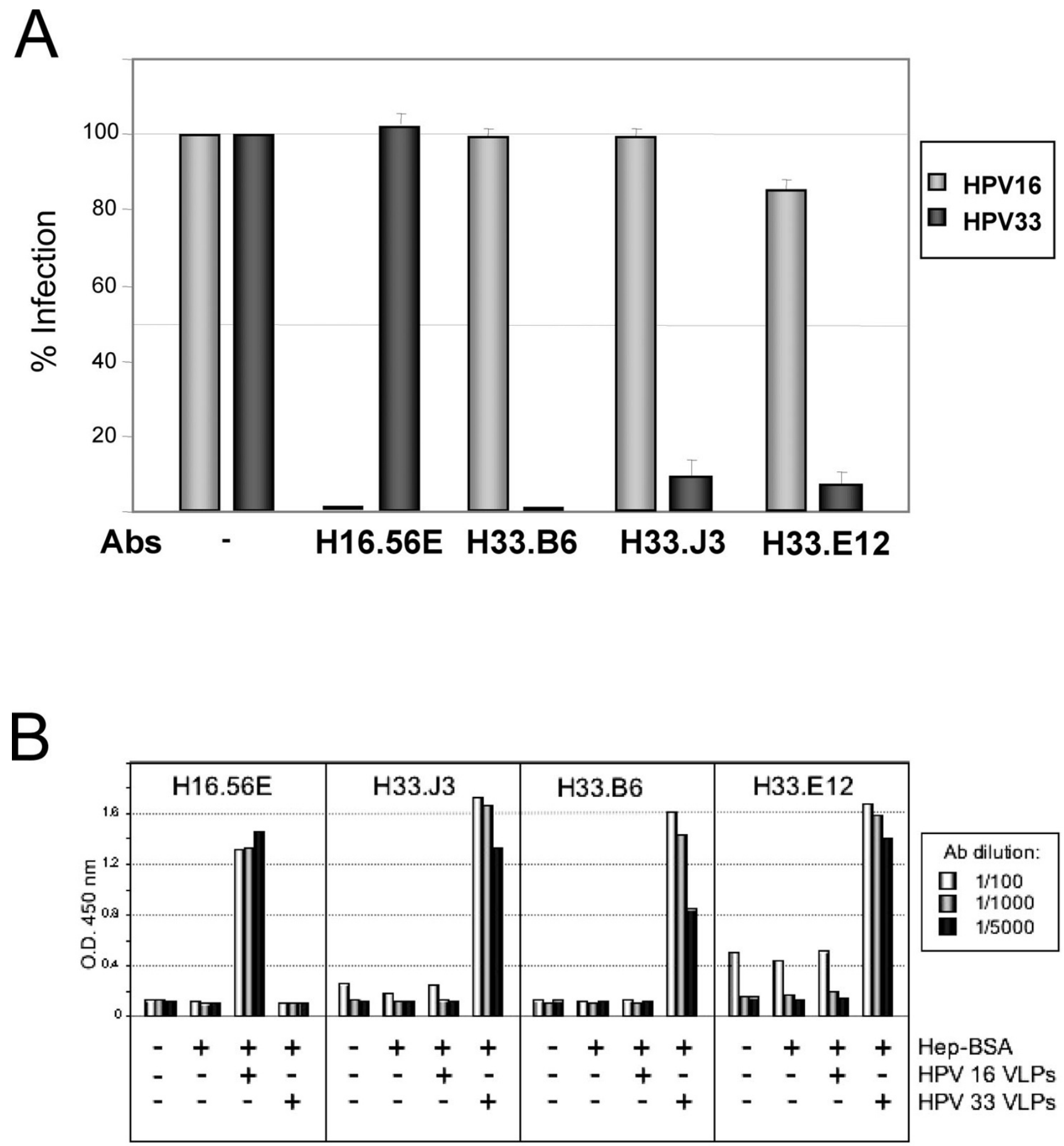

Figure I

Type-specificity of HPV-reactive antibodies. A) Infection of human 293TT cells with HPVI6 and HPV33 pseudovirions in the presence of type-specific neutralizing antibodies. Infectious events unaffected by HPVI6-specific (mAb HI6.56E) or HPV33specific (mAbs H33.B6, H33.J3) monoclonal antibodies were monitored $72 \mathrm{hrs}$ post infection. B) Interaction of type-specific antibodies with HPVI6 and HPV33 virus-like particles (VLPs) in a Heparin-BSA ELISA assay. All three antibodies displayed typespecificity. Although background binding of $\mathrm{mAb} \mathrm{H} 33 . \mathrm{EI} 2$ is significantly increased, specific binding is also restricted to particles of HPV type 33. 


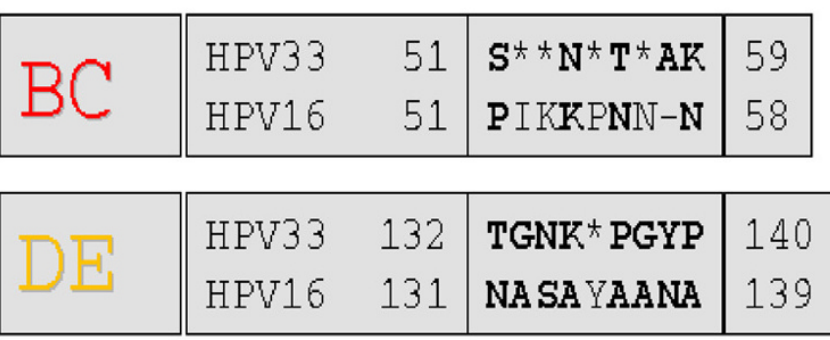

\begin{tabular}{|l||ll|l|l|}
\hline HGa & HPV33 & 260 & F**** TL**A & 270 \\
HPV16 & 260 & LFNRAGAVGEN & 270 \\
\hline
\end{tabular}

\begin{tabular}{|l|ll|l|l|}
\hline FGb & HPV33 & 282 & T** SIQ**AF & 291 \\
HPV16 & 282 & STANLASSNY & 291 \\
\hline
\end{tabular}

\begin{tabular}{|l||ll|l|l|}
\hline HI & HPV33 & 346 & TQV-**DS****E & 357 \\
HPV16 & 346 & AAISTSETTYKNT & 358 \\
\hline
\end{tabular}

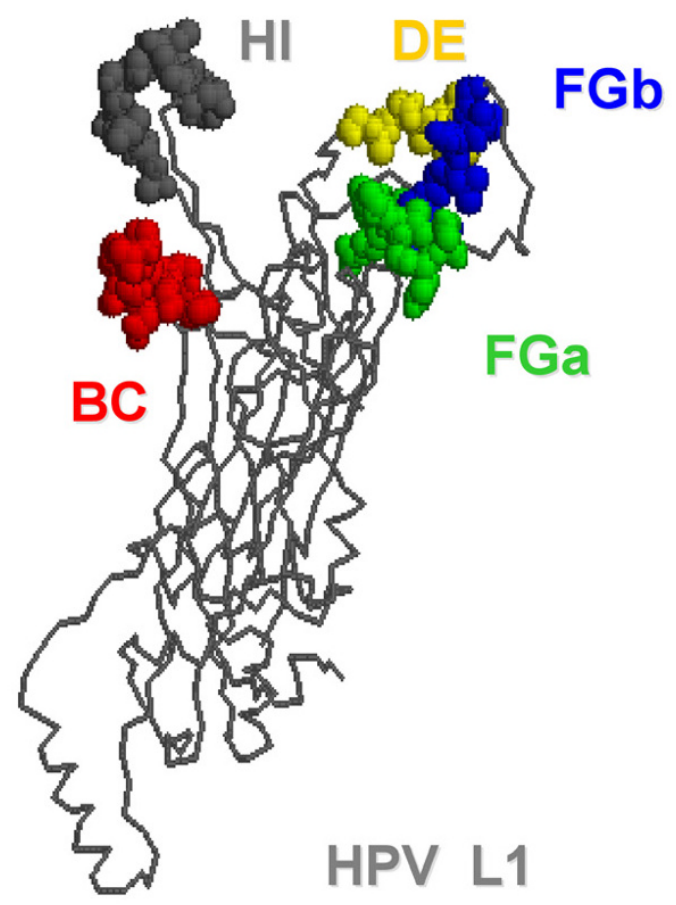

Figure 2

Determinants of type-specificity. Alignment of amino acid sequences in surface-exposed loops of capsid proteins LI of HPVI 6 and HPV33. Divergent amino acids are listed; identical amino acids are marked by asterisks. On the right, localization of these hyper variable loops in the LI monomer is shown. Modeling by RasMol was based on the monomeric structure of the HPVI 6 capsid protein LI.

Binding of monoclonal antibodies to hybrid L1 protein was first tested by immunofluorescence under non-denaturing conditions (Fig. 3). Reactivity of H33.J3 with hybrid particles was lost by exchanging the BC loop but was retained after replacement of the other loops (Fig. 3A). This suggests that the BC loop is the binding site for H33.J3 and that exchange of neighboring surface loops results in conformationally intact L1 assemblies. HPV16 L1 hybrid particles became reactive with this antibody when the HPV33 BC loop, but not the DE, FG, and HI loops, were ectopically expressed on HPV16 (Fig 3B). Reactivity of H16:56E with HPV16:33BC was retained, suggesting that this antibody recognizes a different epitope and, in addition, that this hybrid L1 protein also forms conformationally intact assemblies.
The epitope recognized by the H33.B6 antibody was shown to be more complex, as exchange of loops DE or FGb resulted in the loss of reactivity. Vice versa, introduction of both HPV33 loops into HPV16 L1 transferred reactivity of H33.B6 to the HPV16:33DE/FGb hybrid (Fig. 3B). Surprisingly, exchange of the DE loop alone was sufficient to render HPV16:33DE reactive with this antibody. However, the concomitant exchange of the DE and FGa loops abrogated the binding of H33.B6 with HPV16:33DE/FGa. Therefore, without being part of the epitope, the FGa loop has significant influence on the conformation of the DE loop and thus contributes to the conformation recognized by H33.B6.

The monoclonal antibody H33.E12 binding site also displays a high level of complexity. Individual swapping of loops DE, FGa, and FGb results in the loss of binding to 


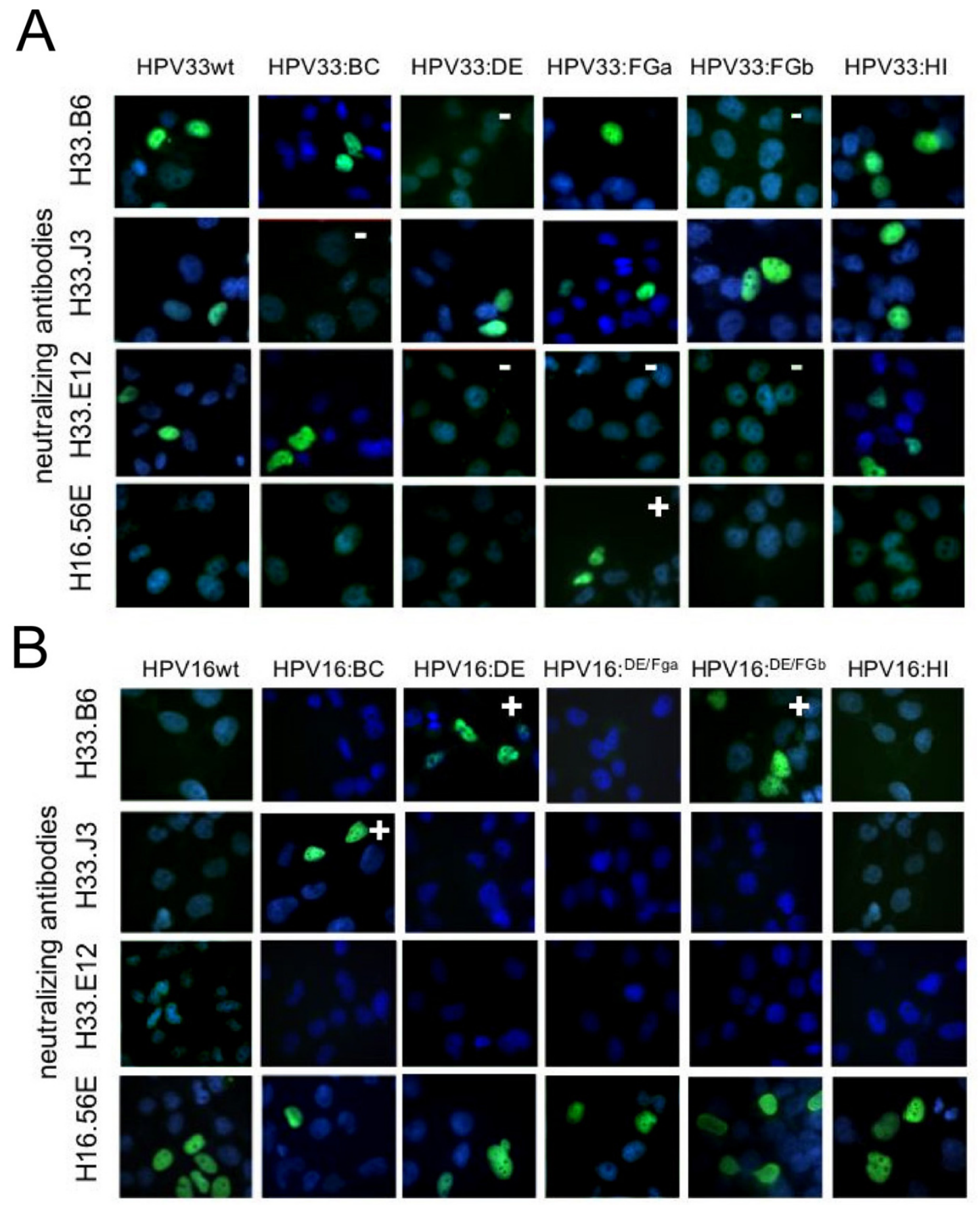

Figure 3

Epitope mapping of type-specific antibodies. A) Elimination of HPV33-specific epitopes by loop exchanges in capsid protein LI. Recombinant HPV LI capsid proteins expressed in HUTK- cells were tested by immunofluorescence analysis for the presence of epitopes for antibodies H 16.56E, H33.EI2, H33.J3 and H33.B6. Loss of reactivity is marked by (-), gain of antibody reactivity by $(+)$. B) Functional transfer of HPV33-specific epitopes to HPV 16 by loop swapping, leading to reactivity $(+)$ with the respective HPV33-specific antibody. Note that the correct presentation of corresponding epitopes is also influenced by neighboring loops. 
HPV33 hybrid L1 proteins (Fig. 3A), whereas the exchange of the $\mathrm{BC}$ and $\mathrm{HI}$ loops had no effect. In contrast to H33.B6, transfer of individual or two combined HPV33 loops onto HPV16 did not result in the reconstruction of the epitope. Unfortunately, we were not successful in the construction of hybrid 16L1 protein carrying all three HPV33 loops required for binding of H33.E12. Using our HPV16:33 chimeric particles, we could also show that the FGa loop is an important part of the H16.56E epitope, since only HPV33:16FGa particles were recognized by this antibody. Vice versa, the fact that all HPV16:33 chimeras were still recognized by this antibody demonstrates that the H16.56E binding site is not a one-loop epitope but rather formed by discontiguous sequences of the L1 protein.

To confirm the validity of our immunofluorescence approach for measuring conformation-dependent antibody binding, we generated and purified hybrid HPV33:16BC VLPs, using recombinant vaccinia viruses and HPV16:33BC after transfection of codon-optimized L1. Reactivity of the monoclonal antibodies with VLPs was measured in a heparin-BSA ELISA (Fig. 4). Swap of the $\mathrm{BC}$ loop resulted in the loss of reactivity of hybrid HPV33:16BC with H33.J3 and a gain of reactivity with H16:33BC. Binding of H33.B6 and H16.56E were not affected by this exchange and solely dependent on the backbone (33L1 for HPV33:16BC and 16L1 for HPV16:33BC) of the chimeric L1 molecules.

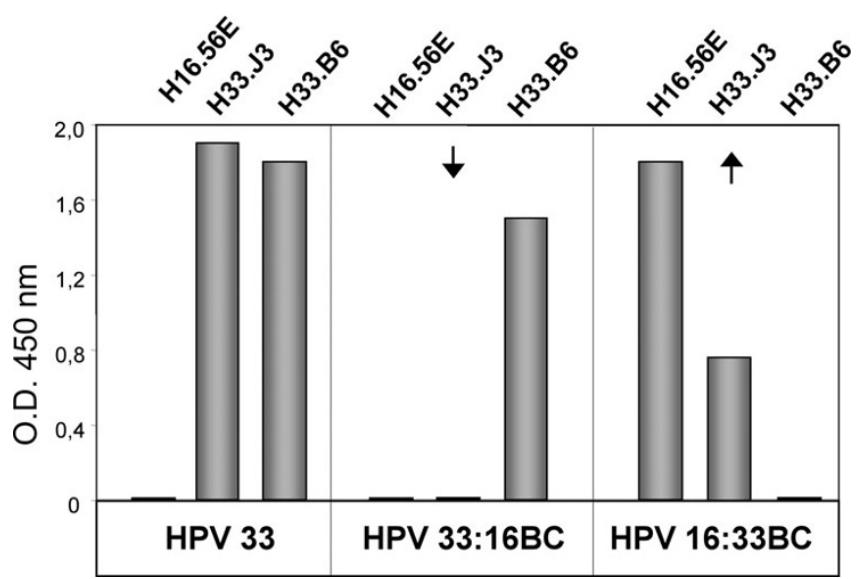

Figure 4

Heparin-BSA ELISA. Analysis of epitope expression on wild type (HPV33) and chimeric (HPV33:16BC and HPV 16:33BC) VLPs bound to Heparin-coated ELISA plates using type-specific antibodies HI6.56E, H33.J3 and H33.B6. Exchange of aa 5I-58 (BC-loop of capsid protein $\mathrm{LI}$ ) results in the loss or gain of reactivity with antibody $\mathrm{H} 33 . \mathrm{J} 3$.

\section{Neutralization of hybrid pseudoviruses}

To exemplarily demonstrate that the transfer of HPV33specific epitopes is functional, hybrid pseudovirions HPV16:33BC were generated that contain the HPV33 BC loop in the context of HPV16, following a published protocol [24]. The mutant was cotransfected with the HPV16 wtL2 expression plasmid and a GFP-expressing marker plasmid to be packaged. The mutant protein efficiently assembled with the L2 protein and the marker plasmid into pseudoviruses that were used in subsequent neutralization assays. As shown in Fig. 5, HPV16:33BC and wt HPV33, but not wt HPV16 pseudovirions, were efficiently neutralized by H33.J3. Hybrid viruses were not neutralized by H33.B6 and H33.E12. These data clearly demonstrate the functional expression of the heterotypic epitope on HPV16.

\section{Discussion}

A variety of neutralizing epitopes are expressed on the capsid surface of human papillomaviruses. So far, neutralizing antibody binding sites for HPV6, 11, 16, 31, and 52 have been mapped to the hyper variable surface loops $\mathrm{BC}$, DE, FG, and $\mathrm{HI}$ of the major capsid protein L1 $[17,19,20,25-27]$. In addition, one neutralizing epitope has been recently identified in the carboxyl-terminal arm of HPV16 (aa 430-450) [28]. The complexity of these epitopes differs considerably among the monoclonal antibodies analyzed so far. We have now demonstrated the involvement of the $\mathrm{BC}, \mathrm{DE}$, and FG surface loops of HPV33 L1 in the induction of type-specific immune responses. H33.J3 recognizes a conformation which solely depends on the presence of the BC loop (Fig. 6A, $D)$. This seems to be a rare event, since most epitopes of

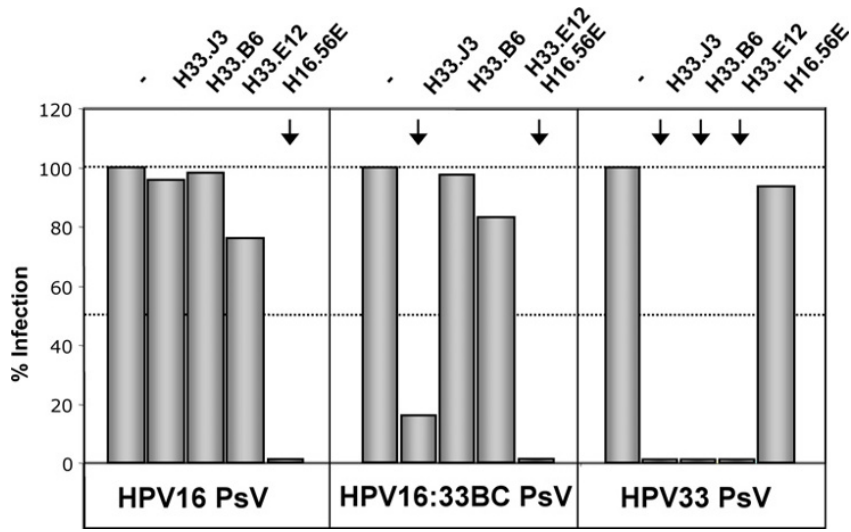

Figure 5

Neutralization of HPV pseudovirus infection of 293TT cells by type-specific antibodies. In contrast to wt HPVI6 and HPV33 pseudovirions, HPVI6:33BC pseudovirions are neutralized by the HPVI6-specific HI6.56E as well as the HPV33-specific H33.J3 antibodies. Infection was monitored $72 \mathrm{~h}$ post infection. 

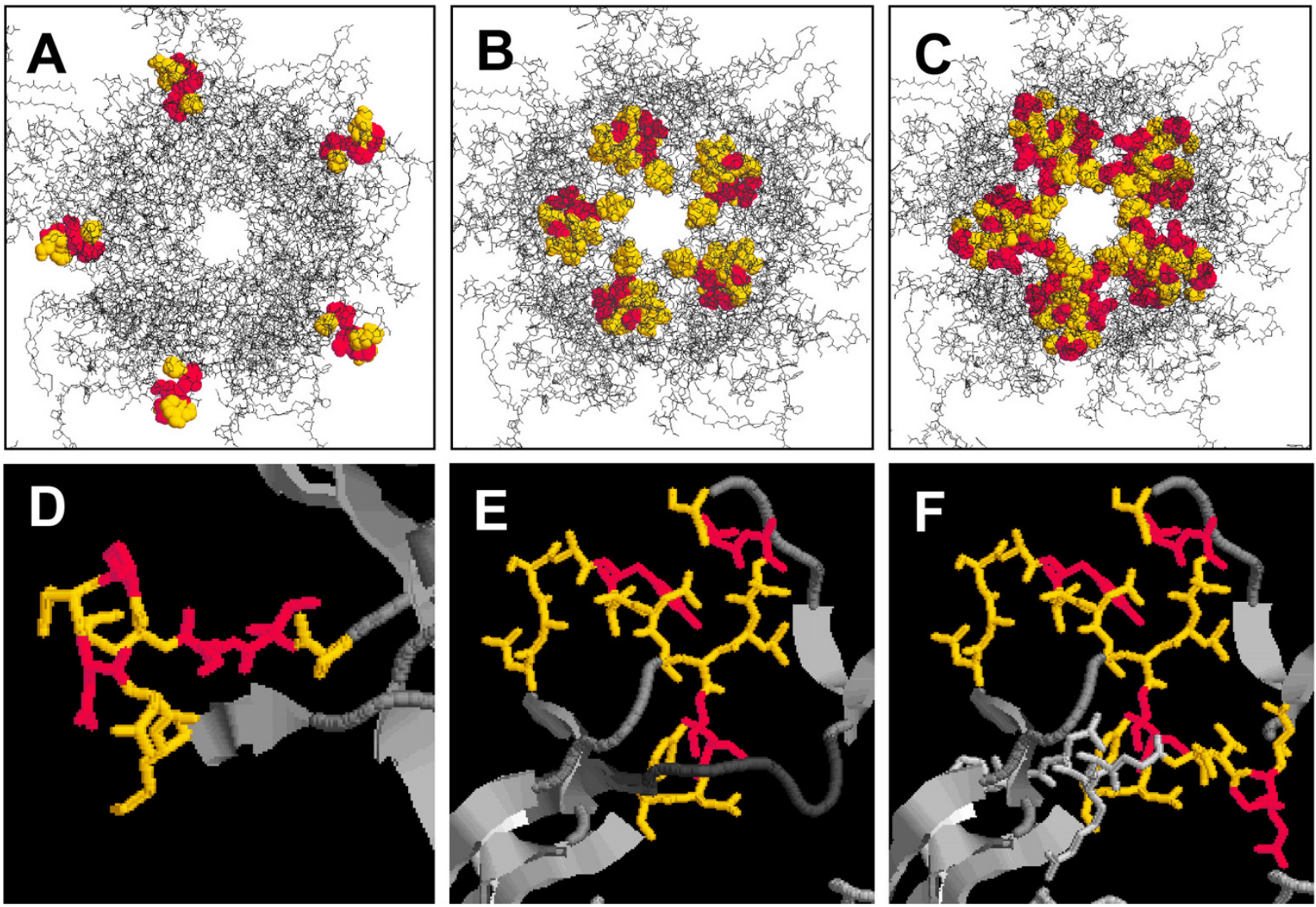

Figure 6

Epitopes of HPV33-specific antibodies on the pentameric LI capsomere. RasMol pictures showing the epitope patterns for mAb H33.J3 (A), mAb H33.B6 (B) and mAb H33.EI2 (C). Variations in the complexity of the epitopes (D-F), ranging from a single loop (D; H33.J3 epitope), two neighboring loops (E, H33.B6 epitope), to at least three loops (F; H33.EI2 epitope). Type-specific amino acids are shown in yellow, conserved amino acids in red).

neutralizing antibodies recognize conformations depending on more than one loop. By swapping $\mathrm{BC}$ loops, the binding and neutralization capacity of this HPV33-specific antibody was easily transferable onto HPV16. The H33.J3 epitope is determined by amino acids $51-58$ and is located at the vertices of capsomeres. Only very few antibodies specific for HPV6 and 11 have been reported to bind this loop [27], and no HPV high-risk type-specific antibody other than H33.J3 has been mapped to this region so far. This may explain the unique properties of this antibody, which does not interfere with binding of particles to the primary HPV attachment receptor, heparan sulfate proteoglycan, and its characteristic feature to preferentially neutralize cell-bound rather than free pseudoviruses [29].

We demonstrated that a more complex epitope is recognized by H33.B6 (Fig. 6B, E). Both the DE and the FGb loop are necessary for binding. Our data also suggest that the FGa loop contributes to the conformation recognized by H33.B6 without being part of the binding site. This is not surprising since all three loops are in intimate proximity to each other and other monoclonal antibodies have also been shown to be influenced by more than one of these loops [20]. The H33.E12 antibody is dependent on loops DE, FGa, and FGb, since replacement of each of these loops for HPV16 resulted in the loss of reactivity. This defines the H33.E12 binding site as an even more complex epitope (Fig. 6C, F). The previously observed partial cross-reactivity of H33.J3 with HPV45, 58, and 59 [16] is most likely due to the complex binding site of this antibody. However, in most cases, cross-reaction might not be sufficient for cross-protection.

Using the HPV16:33BC chimera in pseudovirus neutralization assays, we have also shown that the $\mathrm{BC}$ hyper vari- 
able loop swap not only transfers the binding ability of H33.J3 but also the neutralizing capacity to HPV16. This result suggests that it should be possible to generate HPV hybrid particles that elicit an immune response directed to more than one HPV type. Because of the complexity involving loops DE, FG, and also probably HI [20], which all can contribute to the conformational binding site of a given antibody, targeting loops that are clearly separated seems to be more promising. In addition to the $\mathrm{BC}$ loop, the carboxyl terminal arm is probably a good candidate for such an approach. Only few antibodies that are directed against these regions, which were obtained after experimental immunization of animals, have been described in the literature so far. This could possibly indicate that these epitopes are not immunodominant. On the other hand, a recent analysis of the humoral immune response induced by natural infection with HPV6 and HPV11 did reveal that all L1 surface loops induced efficient immune responses, and failed to identify any immunodominant epitopes [30], suggesting that each hyper variable loop may contribute equally to the induction of virus neutralizing antibodies.

\section{Conclusion}

HPV16, 18, 31 and 33 are the four most prevalent HPV high risk types in cervical cancer. So far, HPV31 and 33 are not included in current vaccines. Construction of a multivalent prophylactic vaccine based on chimeric particles should be facilitated by selective combination of simple rather than complex neutralizing epitopes. We have shown here that various surface exposed hyper variable loops of the major capsid protein L1 of HPV33 contribute to the induction of a virus-neutralizing humoral immune response. The complexity of the identified conformational epitopes ranges from rather simple structures, consisting of only one loop, e.g. the BC loop, to epitopes to which several loops contribute. Our data suggest that it should be possible to generate chimeric polyvalent HPV particles that could serve as an intertypic vaccine targeting several HPV types at a time.

\section{Methods \\ Cell lines and antibodies}

The osteosarcoma cell line HuTK-143B [31] was grown at $37^{\circ} \mathrm{C}$ in Dulbecco's modified Eagle medium (DMEM) supplemented with $10 \%$ fetal calf serum and antibiotics. The human embryonic kidney cell line 293TT [24] was maintained in DMEM/10\% FCS with $1 \%$ Glutamax I and $1 \%$ non-essential amino acids (Invitrogen). Three conformation-dependent, neutralizing mouse monoclonal antibodies, H33.B6 (IgG2a), H33.E12 (IgG2a) and H33.J3 (IgG2b), respectively, with specificity for HPV33 were kindly provided by N. D. Christensen, Hershey, PA. The HPV16-neutralizing mAb H16.56E, was generated by immunization of mice with HPV16 VLPs, and used as previously reported $[32,33]$.

\section{Construction of hybrid LI capsomers by site-directed mutagenesis}

Type-specific amino acids in hypervariable loops of the HPV33- and HPV16 L1 capsid proteins were identified by CLUSTAL amino acid sequence alignment [34]. For generation of HPV33:16 hybrid virus-like-particles, various loop sequences of the HPV33 L1 capsid protein (BC, DE, FGa, FGb, HI; Fig. 2) were exchanged by the corresponding amino acids of HPV16 by introducing codon-modified sequences from p16L1h [35] into pTM33L1 [12]. HPV16:33 hybrids were generated reciprocally, using the codon-modified pUF3hu16L1 vector and codon-modified loop sequences of HPV33 L1. Overlap extension PCR [36] was used to introduce multiple substitutions simultaneously. Pairs of PAGE-purified mutagenesis primers with $100 \%$ complementarity (Table 1 ) were purchased from Invitrogen and PCR was carried out using puReTaq Readyto-go PCR-beads (Amersham Biosciences). In a first step two separate PCR reactions were prepared to generate fragments in forward and reverse orientations, both carrying the desired mutations. Thereby, the reverse mutagenesis primer was used together with an outer forward primer, the forward mutagenesis primer in combination with an outer reverse primer. L1 expression plasmids were used as template and PCR was performed for 40 cycles with denaturation at $95^{\circ} \mathrm{C}$ for 45 seconds, annealing at $42^{\circ} \mathrm{C}$ for $1 \mathrm{~min}$ and elongation at $72^{\circ} \mathrm{C}$ for $2 \mathrm{~min}$. PCR fragments generated by these PCRs were purified by agarose gel electrophoresis, followed by Jetsorp gel extraction prior to their use in subsequent reactions. Because of an average overlap of $60 \mathrm{bp}$ between appropriate fragments, these sequences were hybridized by pre-extension PCR [37], in which the 3 'overlap of each strand acts as a primer for the extension of the complementary strand. This was done by 2 cycles with denaturation at $95^{\circ} \mathrm{C}$ for 5 min and annealing at $72^{\circ} \mathrm{C}$ for $2 \mathrm{~min}$. Resulting products were PCR-amplified by addition of the outer primers of step 1 (conditions: denaturation at $95^{\circ} \mathrm{C}, 45 \mathrm{sec}$; annealing at $50-56^{\circ} \mathrm{C}, 1 \mathrm{~min}$; elongation at $72^{\circ} \mathrm{C}, 2 \mathrm{~min} ; 35$ cycles). Subsequently, the gel-purified mutant L1 amplimers (sized between 800-1900 bp) were cloned into singular restriction sites in the transfer vectors pUF3hu16L1 or pTM33L1 to generate the HPV16/HPV33 or HPV33/ HPV16 hybrid L1-constructs. Ligation mixtures were transfected into chemically competent cells of $E$. coli (DH5 $\alpha$ ). Colonies containing the desired mutations were identified by their newly introduced restriction sites or directly by sequencing. If only one of the two fragments could be generated in the first PCR round, the purified fragment was used in a following PCR as a megaprimer. The fragment was added in excess over the plasmid template and combined with a counter-directed common 
Table I: Codon optimized sequences of mutagenesis primers

\begin{tabular}{|c|c|}
\hline Constructs & Sequences for primers (listed 5' to 3') \\
\hline \multirow[t]{2}{*}{ HPV33:BC } & For GGCCATCCATATTTTCCCATCAAGAAGCCCAACAACAACAAATTATTGGTACCC \\
\hline & Rev GGGTACCAATAATTTGTTGTTGTTGGGCTTCTTGATGGGAAAATATGGATGGCC \\
\hline \multirow[t]{2}{*}{ HPV33:DE } & For TTTGATGACATCGAAAACGCCAGCGCCTACGCCGCCAACGCCGGTGCTGATAATAGG \\
\hline & Rev CCTATTATCAGCACCGGCGTTGGCGGCGTAGGCGCTGGCGTTTTCGATGTCATCAAA \\
\hline \multirow[t]{2}{*}{ HPV33:FGa } & For ATGTTTGTAAGACACCTGTTCAACAGGGCCGGCGCCTACGGCGAGAACGTTCCCGATGACCTG \\
\hline & Rev CAGGTCATCGGGAACGTTCTCGCCGTAGGCGCCGGCCCTGTTGAACAGGTGTCTTACAAACAT \\
\hline \multirow[t]{2}{*}{ HPV33:FGb } & For ATTAAAGGTTCAGGAAGCACCGCCAACCTGGCCAGCAGCAACTACTTTCCCACTCCTAGTGG \\
\hline & Rev CCACTAGGAGTGGGAAAGTAGTTGCTGCTGGCCAGGTTGGCGGTGCTTCCTGAACCTTTAAT \\
\hline \multirow[t]{2}{*}{ HPV33:HI } & For AATATGACTTTATGCGCCGCCATCAGCACCAGCGAGACCACCTACAAGAACAACAATTTTAAAGAATATATAAG \\
\hline & Rev CTTATATATTCTTTAAAATTGTTGTTCTTGTAGGTGGTCTCGCTGGTGCTGATGGCGGCGCATAAAGTCATATT \\
\hline \multirow[t]{2}{*}{ HPVI6:BC } & For GGCCACCCCTACTTCAGCATCAAGAACCCCACCAACGCCAAGAAGATCCTGGTGCCC \\
\hline & Rev GGGCACCAGGATCTTCTTGGCGTTGGTGGGGTTCTTGATGCTGAAGTAGGGGTGGCC \\
\hline \multirow[t]{2}{*}{ HPVI6:DE } & For ACCGGCAACAAGTACCCCGGCCAGCCCGGCGTGGACAACAGGGAGTGCATCAGCATGGAC \\
\hline & Rev CCTGTTGTCCACGCCGGGCTGGCCGGGGTACTTGTTGCCGGTCTCGGTGTCGTCCAG \\
\hline \multirow[t]{2}{*}{ HPVI6:FGa } & For ATGTTCGTGAGGCACTTCTTCAACAGGGCCGGCACCCTGGGCGAGGCCGTGCCCGACGACCTG \\
\hline & Rev CAGGTCGTCGGGCACGGCCTCGCCCAGGGTGCCGGCCCTGTTGAAGAAGTGCCTCACGAACAT \\
\hline \multirow[t]{2}{*}{ HPV 16:FGb } & For ATCAAGGGCAGCGGCACCACCGCCAGCATCCAGAGCAGCGCCTTCTTCCCCACCCCCAGC \\
\hline & Rev GCTGGGGGTGGGGAAGAAGGCGCTGCTCTGGATGCTGGCGGTGGTGCCGCTGCCCTTGAT \\
\hline \multirow[t]{2}{*}{ HPVI6:HI } & For AACATGAGCCTGTGCACCCAGGTGGCCAGCGACAGCACCTACAAGAACGAGAACTTCAAGGAGTACCTG \\
\hline & Rev CAGGTACTCCTTGAAGTTCTCGTTCTTGTAGGTGCTGTCGCTGGCCACCTGGGTGCACAGGCTCATGTT \\
\hline
\end{tabular}

primer, using the following conditions for a total of 35 cycles: denaturation at $95^{\circ} \mathrm{C}$ for $45 \mathrm{sec}$, annealing at $65^{\circ} \mathrm{C}$ for $1 \mathrm{~min}$, elongation at $72^{\circ} \mathrm{C}$ for $2 \mathrm{~min}$. Generation of HPV16:33-hybrids with double loop exchanges occurred successively. One loop was introduced by the approach described above. To introduce the second loop, a forward primer was generated using the hybrid L1 as a template. Subsequently, the fragment served as a megaprimer to amplify the complete expression plasmid with high-fidelity Pwo DNA polymerase for 18 cycles (denaturation for $30 \mathrm{sec}$ at $95^{\circ} \mathrm{C}$, annealing for $1 \mathrm{~min}$ at $50^{\circ} \mathrm{C}$, elongation for $14 \mathrm{~min}$ at $72^{\circ} \mathrm{C}$ ). The PCR product was then digested with DpnI to eliminate methylated template DNA and the remaining mutant plasmids were expressed in E. coli.

\section{Immunofluorescence analysis}

HuTK- cells were grown on glass coverslips overnight, infected with the vaccinia helper virus VTF7-3 for $1 \mathrm{~h}$ (MOI of 5) and subsequently transfected using Lipofectamin plus (Invitrogen) and $1 \mu \mathrm{g}$ transfer plasmid pTM1 carrying wt or mutated HPV33L1 sequences under the control of a T7-promotor. Expression of the pUF3 vector-based wt or hybrid HPV16 L1-constructs occurred by lipofection without any helper viruses. After an incubation period of $10-24 \mathrm{~h}$ at $37^{\circ} \mathrm{C}$ cells were fixed with $2 \%$ paraformaldehyde for $20 \mathrm{~min}$ at room temperature, permeabilized with $0.1 \%$ Nonident P-40 for $15 \mathrm{~min}$ and subsequently blocked in $5 \%$ goat serum dissolved in PBS. Incubations with primary mAbs and secondary Cy2-conjugated Affinipure goat anti-mouse IgG (Jackson Immunoresearch Products) were carried out for $1 \mathrm{~h}$ at $37^{\circ} \mathrm{C}$. Thereafter, coverslips were washed with PBS several times, stained with $0.2 \mu \mathrm{g} / \mathrm{ml}$ Bis-benzimide trihydrochloride (Hoechst 33342; Sigma) and mounted onto slides by using Fluoprep mounting medium (BioMérieux). Pictures were taken using a Zeiss Axiovert $200 \mathrm{M}$ microscope and a Zeiss Axiocam digital camera. The appropriate Axiovision Software 3.0 was used for merging pictures.

\section{Preparation of pseudovirions and VLPs}

HPV33-VLPs and pseudovirions were produced in HuTKcells by infection with recombinant vaccinia viruses vac33L1, vac33L2 and helper virus VTF7-3, as described previously $[12,38]$. For generation of pseudovirions, cells were transfected $24 \mathrm{~h}$ prior to infection with a marker plasmid encoding a dimeric green fluorescent protein (GFP), resulting in HPV particles containing the GFP reporter DNA. Forty-four hours post infection VLPs/PsV were extracted from nuclei by sonication in hypotonic buffer supplemented with $0.5 \%$ NP-40 and purified by buoyant caesium chloride density gradients. HPV16 pseudovirions were prepared as described previously [24] by co-transfection of 293TT cells with pUF3hu16L1 wt or pUF3hu16/33L1-hybrid plasmids, together with pUF3hu16L2 wt and the pEGFPGFP marker plasmid. Subsequent to incubation at $37^{\circ} \mathrm{C}$ for $48 \mathrm{~h}$ cells were lysed and pseudovirions were purified on an OptiPrep gradient. Thereby, lysis of cells was achieved by adding the nonionic detergent Brij58 (Sigma) at a final concentration of $0.5 \%$ in DPBS supplemented with $9.5 \mathrm{mM} \mathrm{MgCl}_{2}$. Lysates were digested over night at $37^{\circ} \mathrm{C}$ with $2 \mathrm{U}$ of Benzonase (Sigma) to complete virus maturation [39]. Subsequently the lysate was mixed with a 0.17 volume of $5 \mathrm{M} \mathrm{NaCl}$, clarified by centrifugation at $1500 \times \mathrm{g}$ for $10 \mathrm{~min}$, loaded 
on top of an OptiPrep step gradient (27\%/33\%/39\% OptiPrep in DPBS- $800 \mathrm{mM} \mathrm{NaCl}$ ) and centrifuged for $4 \mathrm{~h}$ at $234.000 \times \mathrm{g}$. After centrifugation, $250 \mu \mathrm{l}$-fractions were collected by bottom puncture of the tubes and $1 \mu \mathrm{l}$ of each fraction was tested in a pseudovirus infection assay.

\section{Infection and neutralization assays}

Human embryonic kidney 293TT cells were grown overnight in 24-well plates and infected with $1 \mu \mathrm{l}$ of HPV pseudovirions (PsV) in a total volume of $500 \mu \mathrm{l}$ DMEM. Cells were grown at $37^{\circ} \mathrm{C}$ for $72 \mathrm{~h}$ and infectious events were monitored by counting cells with green nuclear fluorescence. To perform virus neutralization assays, PsV were bound to cells for $1 \mathrm{~h}$ at $4^{\circ} \mathrm{C}$, unbound virions were removed and various dilutions of HPV-specific neutralizing antibodies were added to cells in a total volume of 250 $\mu \mathrm{l}$ DMEM. After $1 \mathrm{~h}$ at $37^{\circ} \mathrm{C}$ the culture medium was replaced and incubation was continued for $72 \mathrm{~h}$.

\section{Heparin-based enzyme-linked immunosorbent assays (Hep-BSA ELISA)}

VLP-ELISAs were used to study the interaction of conformationally intact VLPs with heparin and performed as previously described $[29,40]$. Briefly, polysorb microtiter plates (NUNC, Wiesbaden, Germany) were coated overnight with 100 ng of heparin-BSA/well in phosphate-buffered saline (PBS), washed and subsequently blocked with BSA $(50 \mu \mathrm{g} / \mathrm{ml})$ for 30 minutes. Plates were again washed, $100 \mu \mathrm{l} \mathrm{VLPs}(1 \mu \mathrm{g} / \mathrm{ml})$ were added and incubated for $1 \mathrm{~h}$ at $37^{\circ} \mathrm{C}$. Unbound particles were eliminated by washing. HPV type-specific antibodies H16.56E, H33.B6, H33.J3 and $\mathrm{H} 33 . \mathrm{E} 12$ were added for $1 \mathrm{~h}$ at $37^{\circ} \mathrm{C}$ at the indicated concentrations $(1: 100-1: 5000)$. After washing three times with PBS-Tween 20 (PBS-T), $100 \mu$ l horseradish peroxidase-coupled secondary antibodies (goat anti-mouse IgG; 1:10.000 in PBS-T) obtained from Jackson Immunochemicals were added and incubated for additional 30 min at $37^{\circ} \mathrm{C}$. Plates were washed and developed with ready to use trimethyl benzidine (KPL). The reaction was stopped after $10 \mathrm{~min}$ at $37^{\circ} \mathrm{C}$ with $100 \mu \mathrm{l} 1 \mathrm{~N} \mathrm{HCl}$. Absorbance was measured at $450 \mathrm{~nm}$ using a Multiscan EX (Thermo Life Sciences).

\section{Visualization of epitopes by RasMol}

The RasMol program is a molecular graphics visualisation tool for macromolecular structures [41]. Localization of amino acids in loops structures of capsid protein L1 from HPV16 or HPV33 was based on the atomic coordinates of the HPV16 major capsid protein L1 [17] and visualized using the PDB file 1DZL in the RasMol program.

\section{Competing interests}

The author(s) declare they have no competing interests with this publication.

\section{Acknowledgements}

We gratefully acknowledge Neil D. Christensen, (Penn State Hershey Medical Center, PA, USA) for providing HPV33-specific monoclonal antibodies, Kirsten Freitag (University of Mainz) for technical help and Gilles Spoden, Maren Knappe and Luise Florin (University of Mainz) for support or critical reading of the manuscript.

\section{References}

I. Walboomers JM, Jacobs MV, Manos MM, Bosch FX, Kummer JA, Shah KV, Snijders PJ, Peto J, Meijer CJ, Munoz N: Human papillomavirus is a necessary cause of invasive cervical cancer worldwide. J Pathol 1999, 189:12-19.

2. Lorincz AT, Reid R, Jenson AB, Greenberg MD, Lancaster W, Kurman $\mathrm{RJ}$ : Human papillomavirus infection of the cervix: Relative risk associations of I 5 common anogenital types. Obstet Gynecol 1992, 79:328-337.

3. Munoz N, Bosch FX, de Sanjose S, Herrero R, Castellsague X, Shah KV, Snijders PJ, Meijer CJ: Epidemiologic classification of human papillomavirus types associated with cervical cancer. $N$ Engl J Med 2003, 348:518-527.

4. Koutsky LA, Ault KA, Wheeler CM, Brown DR, Barr E, Alvarez FB, Chiacchierini LM, Jansen KU: A controlled trial of a human papillomavirus type I 6 vaccine. N Engl J Med 2002, 347:|645-|65I.

5. Harper DM, Franco EL, Wheeler C, Ferris DG, Jenkins D, Schuind A, Zahaf T, Innis B, Naud P, de Carvalho NS, Roteli-Martins CM, Teixeira J, Blatter MM, Korn AP, Quint W, Dubin G: Efficacy of a bivalent LI virus-like particle vaccine in prevention of infection with human papillomavirus types 16 and 18 in young women: $A$ randomised controlled trial. Lancet 2004, 364: I 757-I765.

6. Villa LL, Costa RL, Petta CA, Andrade RP, Ault KA, Giuliano AR, Wheeler CM, Koutsky LA, Malm C, Lehtinen M, Skjeldestad FE, Olsson SE, Steinwall M, Brown DR, Kurman RJ, Ronnett BM, Stoler MH, Ferenczy A, Harper DM, Tamms GM, Yu J, Lupinacci L, Railkar R, Taddeo FJ, Jansen KU, Esser MT, Sings HL, Saah AJ, Barr E: Prophylactic quadrivalent human papillomavirus (types 6, I I, I6, and I 8) LI virus-like particle vaccine in young women: A randomised double-blind placebo-controlled multicentre phase II efficacy trial. Lancet Oncol 2005, 6:27I-278.

7. Volpers C, Schirmacher P, Streeck RE, Sapp M: Assembly of the major and the minor capsid protein of human papillomavirus type 33 into virus-like particles and tubular structures in insect cells. Virology 1994, 200:504-5I2.

8. Rose RC, Bonnez W, Reichman RC, Garcea RL: Expression of human papillomavirus type I I LI protein in insect cells: In vivo and in vitro assembly of virus-like particles. J Virol 1993, 67:1936-1944.

9. Hagensee ME, Yaegashi N, Galloway DA: Self-assembly of human papillomavirus type I capsids by expression of the LI protein alone or by coexpression of the LI and L2 capsid proteins. I Virol 1993, 67:315-322.

10. Kirnbauer R, Booy F, Cheng N, Lowy DR, Schiller JT: Papillomavirus LI major capsid protein self-assembles into virus-like particles that are highly immunogenic. Proc Natl Acad Sci U S A 1992, 89: 12 180-12184.

II. Roden RB, Greenstone HL, Kirnbauer R, Booy FP, Jessie J, Lowy DR, Schiller JT: In vitro generation and type-specific neutralization of a human papillomavirus type 16 virion pseudotype. J Virol 1996, 70:5875-5883.

12. Unckell F, Streeck RE, Sapp M: Generation and neutralization of pseudovirions of human papillomavirus type 33. J Virol I997, 7 I:2934-2939.

13. Pastrana DV, Buck CB, Y Pang YY, Thompson CD, Castle PE, FitzGerald PC, Kruger Kjaer S, Lowy DR, Schiller JT: Reactivity of human sera in a sensitive, high-throughput pseudovirus-based papillomavirus neutralization assay for HPVI 6 and HPVI8. Virology 2004, 32 I :205-216.

14. Christensen ND, Reed CA, Cladel NM, Hall K, Leiserowitz GS: Monoclonal antibodies to HPV-6 LI virus-like particles identify conformational and linear neutralizing epitopes on HPV-I I in addition to type-specific epitopes on HPV-6. Virology 1996, 224:477-486

15. Giroglou T, Florin L, Schafer F, Streeck RE, Sapp M: Human papillomavirus infection requires cell surface heparan sulfate. J Virol 200I, 75: I565-I570. 
16. Combita AL, Touzé A, Bousarghin L, Christensen ND, Coursaget $P$ Identification of two cross-neutralizing linear epitopes within the LI major capsid protein of human papillomaviruses. I Virol 2002, 76:6480-6486.

17. Chen XS, Garcea RL, Goldberg I, Casini G, Harrison SC: Structure of small virus-like particles assembled from the LI protein of human papillomavirus I6. Mol Cell 2000, 5:557-567.

18. Roden RB, Armstrong A, Haderer P, Christensen ND, Hubbert NL, Lowy DR, Schiller JT, Kirnbauer R: Characterization of a human papillomavirus type 16 variant-dependent neutralizing epitope. J Virol 1997, 7 I:6247-6252.

19. Christensen ND, Cladel NM, Reed CA, Budgeon LR, Embers ME Skulsky DM, McClements WL, Ludmerer SW, Jansen KU: Hybrid papillomavirus $L I$ molecules assemble into virus-like particles that reconstitute conformational epitopes and induce neutralizing antibodies to distinct HPV types. Virology 200I, 29 I:324-334.

20. Carter J], Wipf GC, Benki SF, Christensen ND, Galloway DA: Identification of a human papillomavirus type 16-specific epitope on the c-terminal arm of the major capsid protein LI. I Virol 2003, 77:1 I625-1 I632.

21. Fleury MJ, Touzé A, Alvarez E, Carpentier G, Clavel C, Vautherot JF, Coursaget $P$ : Identification of type-specific and cross-reactive neutralizing conformational epitopes on the major capsid protein of human papillomavirus type 31. Arch Virol 2006, I5I:I5II-I523.

22. Rose RC, White WI, Li M, Suzich JA, Lane C, Garcea RL: Human papillomavirus type II recombinant $L I$ capsomeres induce virus-neutralizing antibodies. J Virol 1998, 72:615I-6I54.

23. Fligge C, Schafer F, Selinka H-C, Sapp C, Sapp M: DNA-induced structural changes in the papillomavirus capsid. J Virol 200I, 75:7727-773I.

24. Buck CB, Pastrana DV, Lowy DR, Schiller JT: Efficient intracellular assembly of papillomaviral vectors. J Virol 2004, 78:75I-757.

25. Ludmerer SW, Benincasa D, Mark GE, Christensen ND: A neutralizing epitope of human papillomavirus type II is principally described by a continuous set of residues which overlap a distinct linear, surface-exposed epitope. J Virol 1997, 71:3834-3839.

26. White WI, Wilson SD, Palmer-Hill F], Woods RM, Ghim SJ, Hewitt LA, Goldman DM, Burke SJ, Jenson AB, Koenig S, Suzich JA: Characterization of a major neutralizing epitope on human papillomavirus type 16 LI. J Virol 1999, 73:4882-4889.

27. McClements WL, Wang XM, Ling JC, Skulsky DM, Christensen ND, Jansen KU, Ludmerer SW: A novel human papillomavirus type 6 neutralizing domain comprising two discrete regions of the major capsid protein LI. Virology 200I, 289:262-268.

28. Carter IJ, Wipf GC, Madeleine MM, Schwartz SM, Koutsky LA, Galloway DA: Identification of human papillomavirus type $16 \mathrm{LI}$ surface loops required for neutralization by human sera. J Virol 2006, 80:4664-4672.

29. Selinka H-C, Giroglou T, Nowak T, Christensen ND, Sapp M: Further evidence that papillomavirus capsids exist in two distinct conformations. J Virol 2003, 77:1296I-I2967.

30. Orozco JJ, Carter JJ, Koutsky LA, Galloway DA: Humoral immune response recognizes a complex set of epitopes on human papillomavirus type 6 LI capsomers. J Virol 2005, 79:9503-95I4.

31. Moss B, Elroy-Stein O, Mizukami T, Alexander WA, Fuerst TR: New mammalian expression vectors. Nature 1990, 348:91-92.

32. Sapp M, Kraus U, Volpers C, Snijders PJ, Walboomers JM, Streeck RE: Analysis of type-restricted and cross-reactive epitopes on virus-like particles of human papillomavirus type $\mathbf{3 3}$ and in infected tissues using monoclonal antibodies to the major capsid protein. I Gen Virol 1994, 75:3375-3383.

33. Bergsdorf C, Beyer C, Umansky V, Werr M, Sapp M: Highly efficient transport of carboxyfluorescein diacetate succinimidy ester into Cos7 cells using human papillomavirus-like particles. FEBS Lett 2003, 536:120-124.

34. Thompson JD, Gibson TJ, Plewniak F, Jeanmougin F, Higgins DG: The ClustalX windows interface: flexible strategies for multiple sequence alignmend aided by quality analysis tools. Nucl Acids Res 1997, 24:4876-4882.

35. Leder C, Kleinschmidt JA, Wiethe C, Muller M: Enhancement of capsid gene expression: Preparing the human papillomavirus type 16 major structural gene LI for DNA vaccination purposes. J Virol 200I, 75:920I-9209.
36. Ho SN, Hunt HD, Horton RM, Pullen JK, Pease LR: Site-directed mutagenesis by overlap extension using the polymerase chain reaction. Gene 1989, 77:5I-59.

37. An $Y$, Ji J, Wu W, Lv A, Huang $R$, Wei $Y$ : A rapid and efficient method for multiple-site mutagenesis with a modified overlap extension PCR. Appl Microbiol Biotechnol 2005, 68:774-778.

38. Sapp M, Selinka H-C: Pseudovirions as specific tools for investigation of virus interactions with cells. Methods Mol Biol 2005, 295: $197-212$.

39. Buck CB, Thompson CD, Pang YY, Lowy DR, Schiller JT: Maturation of papillomavirus capsids. J Virol 2005, 79:2839-2846.

40. Rommel O, Dillner J, Fligge C, Bergsdorf C, Wang X, Selinka H-C Sapp M: Heparan sulfate proteoglycans interact exclusively with conformationally intact HPV LI assemblies: Basis for a virus-like particle ELISA. J Med Virol 2005, 75: I | 4-I2I.

41. Homepage for RasMol and OpenRasMol. Molecular graphics visualization software [http://www.rasmol.org]
Publish with Bio Med Central and every scientist can read your work free of charge

"BioMed Central will be the most significant development for disseminating the results of biomedical research in our lifetime. "

Sir Paul Nurse, Cancer Research UK

Your research papers will be:

- available free of charge to the entire biomedical community

- peer reviewed and published immediately upon acceptance

- cited in PubMed and archived on PubMed Central

- yours - you keep the copyright
BioMedcentral 